\title{
MUSCULAR DEFECTS IN THE VENTRICULAR SEPTUM
}

\author{
BY \\ DONALD HEATH, ${ }^{*}$ JAMES W. BROWN, AND WILLIAM WHITAKER \\ From the Regional Cardio-Vascular Centre, City General Hospital and the University Department of Medicine, Royal \\ Hospital, Sheffield
}

Received December 3, 1954

Although defects in the muscular part of the inter-ventricular septum have been recognized since the time of Galen, they are rare. Selzer (1954) states that 90 per cent of isolated ventricular septal defects and virtually all those occurring with other malformations of the heart are located in the membranous septum and he believes that muscular defects are of no clinical importance since they are usually small and decrease in size or close during systole. A similar opinion is held by Kaplan and Robinson (1954) who consider that there is a remarkable absence of symptoms with defects in the muscular portion of the inter-ventricular septum. Such congenital defects may, however, be associated with a dramatic clinical picture as in the case now reported.

\section{CASE REPORT}

A married woman, aged 21 years, was admitted as an emergency with hæmoptysis. She had been short of breath on exertion since infancy and had suffered from coughs and colds every winter. Her parents had noticed that her lips became blue when she was breathless and for this reason had taken her at the age of five years for examination by one of us (J.W.B.) when, on the basis of a loud præcordial systolic murmur, a ventricular septal defect was diagnosed. From the age of six she had had recurrent nose bleeding and her breathlessness on exertion had become worse but she was not cyanosed other than on exertion. At the age of twenty years she had coughed up a little bright red blood and after five weeks of repeated small hæmoptyses had suddenly coughed up a pint of blood. A year later she had had further hæmoptyses and this had continued until five days before her admission when she had complained of a bubbling sensation in her chest and coughed up a further pint of blood. Three days after admission she had a further profuse hæmoptysis and died.

On admission she was a tall thin girl with pallor of the skin and mucous membranes. There were no petechiæ. The fingers were long and tapering but were not clubbed. There was no cyanosis at rest but on slight exertion her lips became blue. The radial pulse was regular at $120 \mathrm{a}$ minute and of poor volume. The blood pressure in the arms was $120 / 80 \mathrm{~mm}$. $\mathrm{Hg}$, and both femoral pulses were palpable and equal. The apex beat was palpable in the sixth left intercostal space just beyond the mid-clavicular line and the character of the cardiac impulse indicated right ventricular hypertrophy. The second heart sound was palpable in the pulmonary area. A loud systolic murmur was present over the whole præcordium but was of maximum intensity in the fourth left intercostal space two inches to the left of the sternum. The second sound in the pulmonary area was abnormally loud and split. The electrocardiogram showed sinus rhythm, clockwise rotation of a vertical heart, and a ventricular pattern of right ventricular hypertrophy (Fig. 1). On radiological examination there was moderate overall cardiac enlargement in the postero-anterior position and evidence of right ventricular hypertrophy in the left anterior oblique view. The pulmonary artery and its main branches were dilated and abnormally pulsatile but the degree of pulsation did not amount to a hilar dance: the vascularity of the lung fields was increased (Fig. 2). There was no evidence of pulmonary tuberculosis and no tubercle bacilli were found in the sputum. The hæmoglobin was $10 \cdot 2 \mathrm{~g}$. per $100 \mathrm{ml}$. Clinically the diagnosis was considered to be a ventricular septal defect with pulmonary hypertension. 


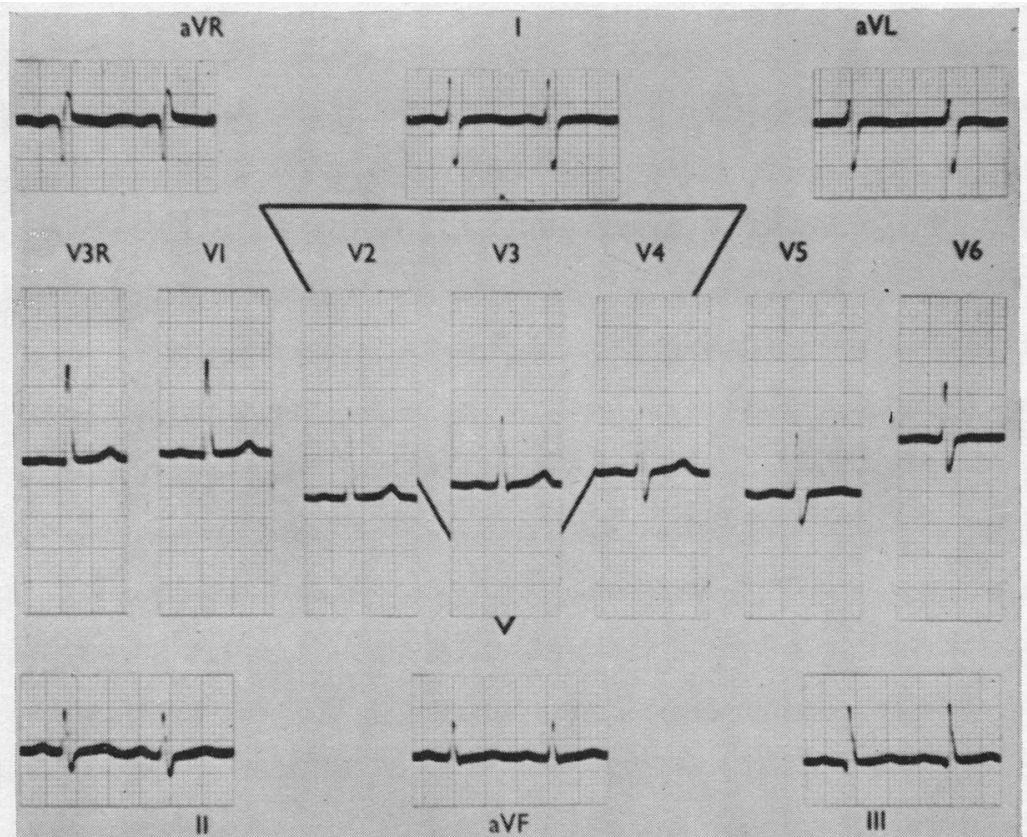

Fig. 1.-Electrocardiogram showing ventricular pattern of right ventricular hypertrophy and clockwise rotation of a vertical heart. $0.5 \mathrm{~cm}$. equals 1 millivolt.

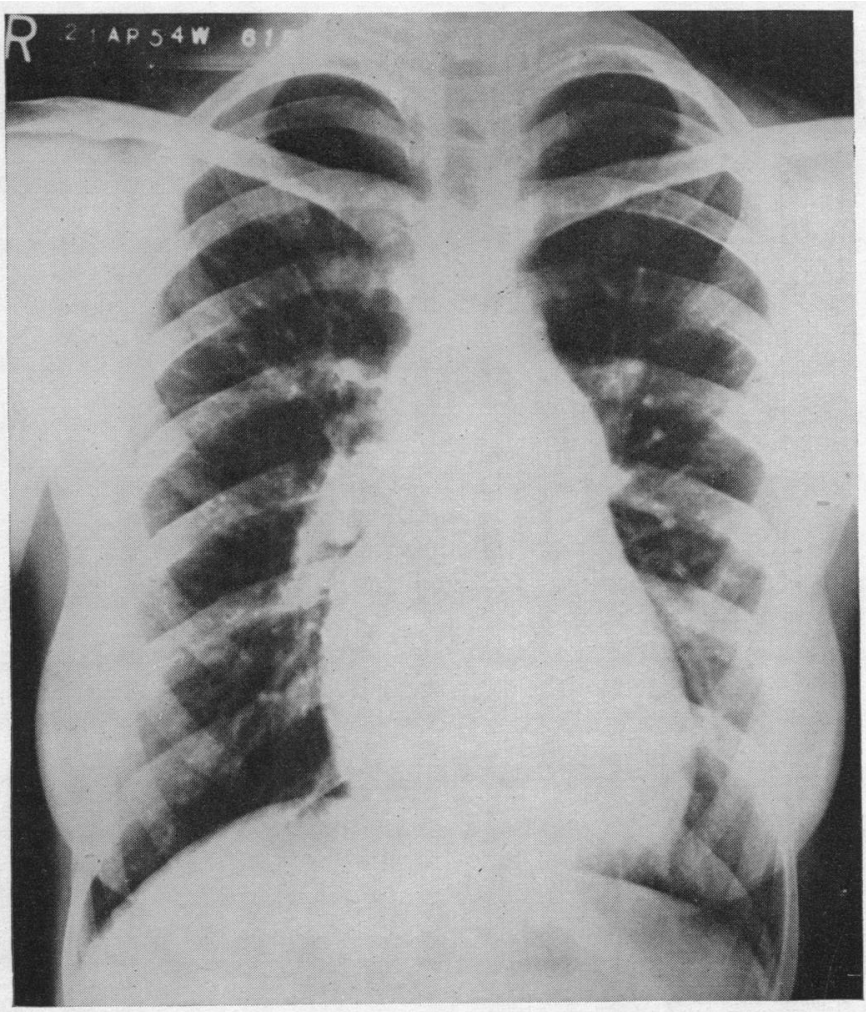

FIG. 2.-Postero-anterior teleradiogram of the chest showing moderate overall cardiac enlargement with prominence of the pulmonary artery and its main branches. 


\section{NECROPSY REPORT}

The heart was enlarged, mainly due to hypertrophy of the right ventricle (Fig. 3). The tricuspid valve was normal; there was no infundibular stenosis and the pulmonary valve was normal. The main pulmonary artery was dilated to twice its normal diameter and flecks of atheroma were present in the extrapulmonary.portions. The left ventricle was not hypertrophied and the mitral valve had three cusps. There was a ventricular septal defect, $2 \mathrm{~cm}$. in diameter, in the region of the apex (Fig. 4). This was traversed by one of the columnæ carneæ from the left ventricle and by one of the chordæ tendineæ of the mitral valve.

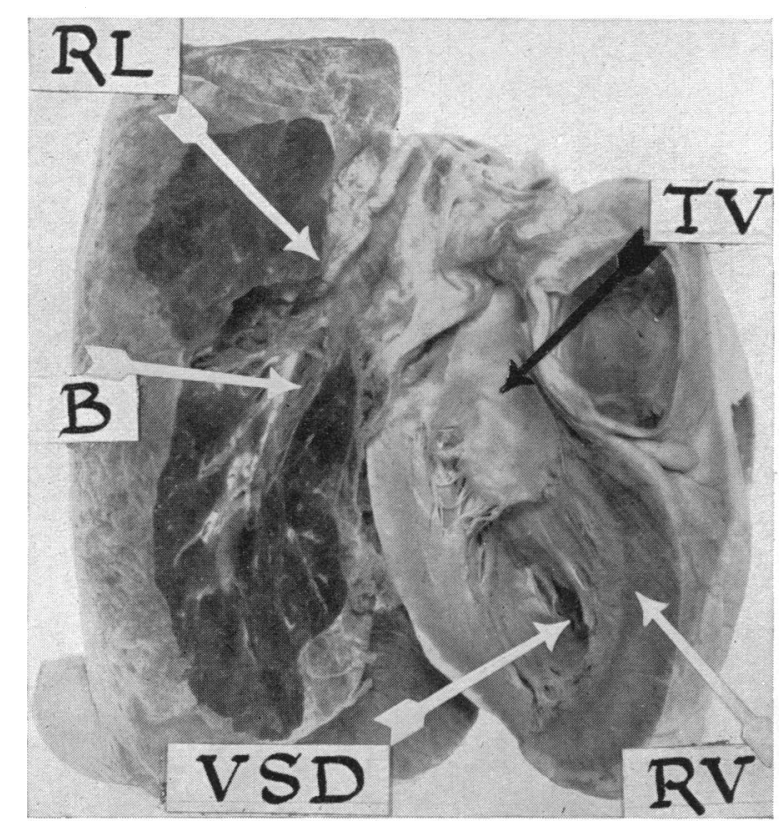

Fig. 3.-The heart and right lung dissected to show the muscular defect in the lower third of the ventricular septum. The right ventricle is hypertrophied. The bronchial tree contains antemortem clot. VSD $=$ Ventricular septal defect. $\mathrm{RL}=\mathrm{Right}$ lung. $\mathrm{TV}=$ Tricuspid valve. $R V=$ Right ventricle. $B=$ Bronchus.

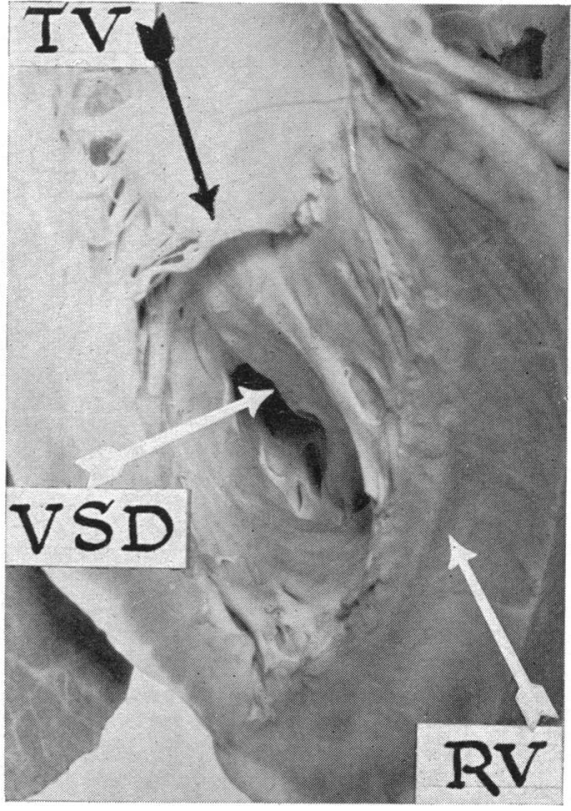

Fig. 4.-Close up view of the muscular defect which is crossed by one of the columnæ carneæ of the left ventricle. There is right ventricular hypertrophy. VSD $=$ Ventricular septal defect. RV= Right ventricle. $T V=$ Tricuspid valve.

There was no defect in the membranous part of the ventricular septum. The ductus arteriosus was not patent and there was no atrial septal defect. The upper lobe of the left lung was solid to the touch and the left upper lobe bronchus was blocked by blood clot (Fig. 3). The stomach was dilated and contained two pints of altered blood.

On histological examination there was no evidence of medio-necrosis of the extrapulmonary elastic arteries. Although atheroma had been noted in the extrapulmonary arteries it was not seen in the intrapulmonary portions. The muscular pulmonary arteries $(100 \mu$ to $1000 \mu)$ showed severe and widespread changes and it was impossible to find a single muscular artery that could be passed as normal (Fig. 5, 6, and 7). The adventitia was thick and fibrous and was infiltrated in many cases by thin wisps of elastic tissue which had split away from the grossly thickened external elastic lamina. The media was hypertrophied with an abnormally thick layer of densely staining, circularly arranged, smooth muscle cells peripheral to the internal elastic lamina. This lamina was very thick and there were fine wisps of elastic tissue spreading into the media. The majority of the muscular arteries were occluded by young fibrous tissue or fibro-elastic tissue which had recanalized in many. Some arteries showed medial aplasia, the external and internal membranes fusing into a single lamina between proliferated intimal tissue and adventitia (Fig. 8). In some cases the media was absent for as much as 40 per cent of the circumference of the vessel and this was particularly in evidence in 


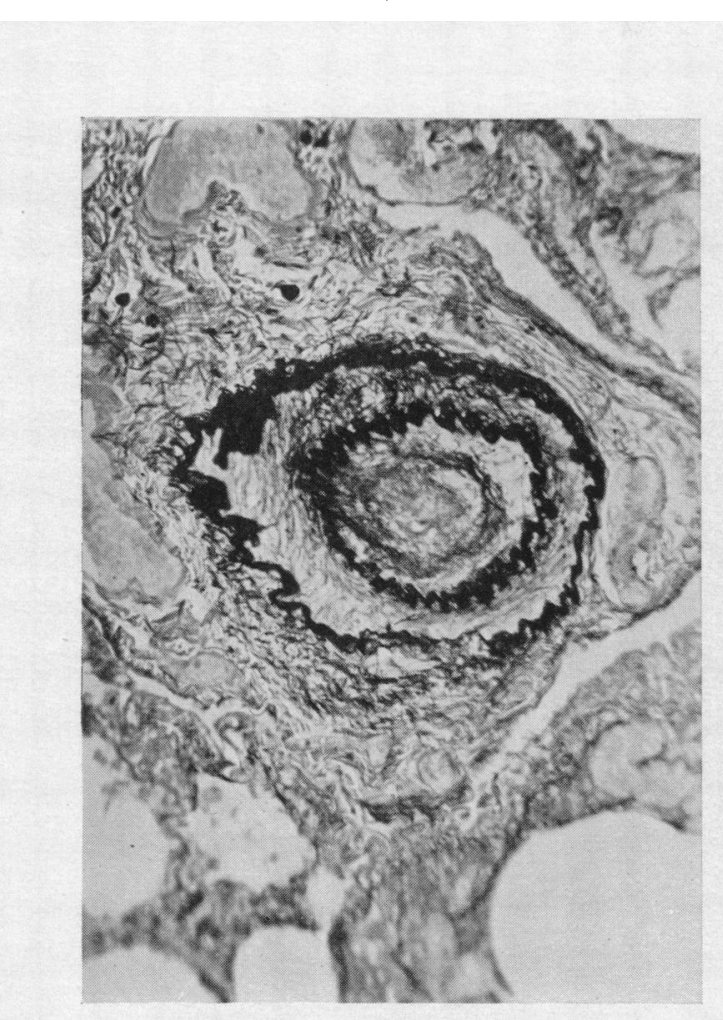

FIG. 5.-Transverse section of muscular pulmonary artery. The media is hypertrophied and both elastic lamina are thick. There is proliferation of fibro-elastic tissue from the intima obliterating the lumen (Stain, Verhoeff/Van Gieson, × 144).

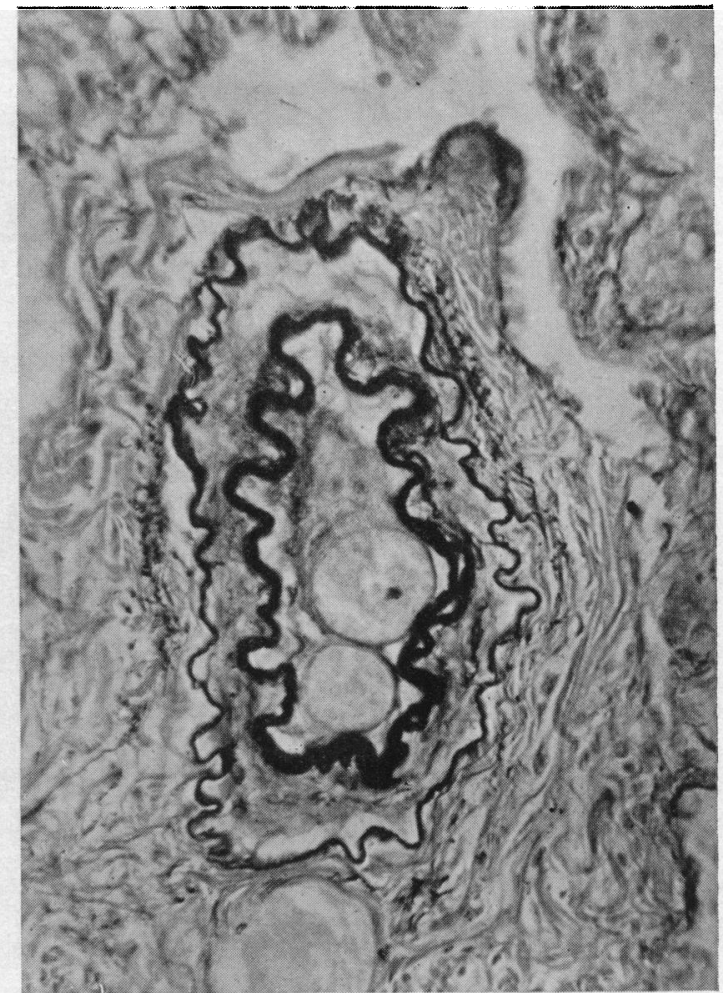

FIG. 6.-Transverse section of muscular pulmonary artery. Recanalization has occurred in the lumen of the vessel blocked by fibro-elastic tissue proliferated from the intima. The internal elastic membrane is very thick (Stain, Verhoeff/Van Gieson, × 290).

the region where the bronchioles opened into the infundibulum. At this site certain of the muscular pulmonary arteries appeared to communicate with vessels whose diameter was greater than that of the parent artery. These vessels, which were lined by fibro-elastic tissue and filled with blood, were at first thought to be aneurysmal sacs, since communications between artery and vessel were frequently seen. The external elastic lamina was thin in some places and in others had broken (Fig. 9). These appearances were different from normal branching of the pulmonary artery where the media and lamina are intact at all other places than that of emergence of the branch the diameter of which is considerably less than that of the parent vessel. However, on examination of serial sections these sacs were found to be grossly dilated branches of the parent vessel. The arterioles (less than $100 \mu$ ) had a thick adventitia and a definite media bounded by distinct internal and external elastic membranes. Brenner (1935) pointed out that the normal arteriole consists of an endothelium lying on a single elastic lamina with no media. The veins showed crescents of sclerotic tissue, partially occluding the lumen.

\section{Discussion}

The symptoms of breathlessness and cyanosis on exertion, frequent coughs and colds, and recurrent hæmoptysis, which occurred in the present case, are similar to those observed in patients with Eisenmenger's complex by Brown et al. (1955) and in other patients with patent ductus arteriosus complicated by pulmonary hypertension by Whitaker et al. (1955); they were considered by these authors to be characteristic of congenital heart disease complicated by severe pulmonary hypertension. There was clinical evidence of pulmonary hypertension in the present patient and cyanosis on 


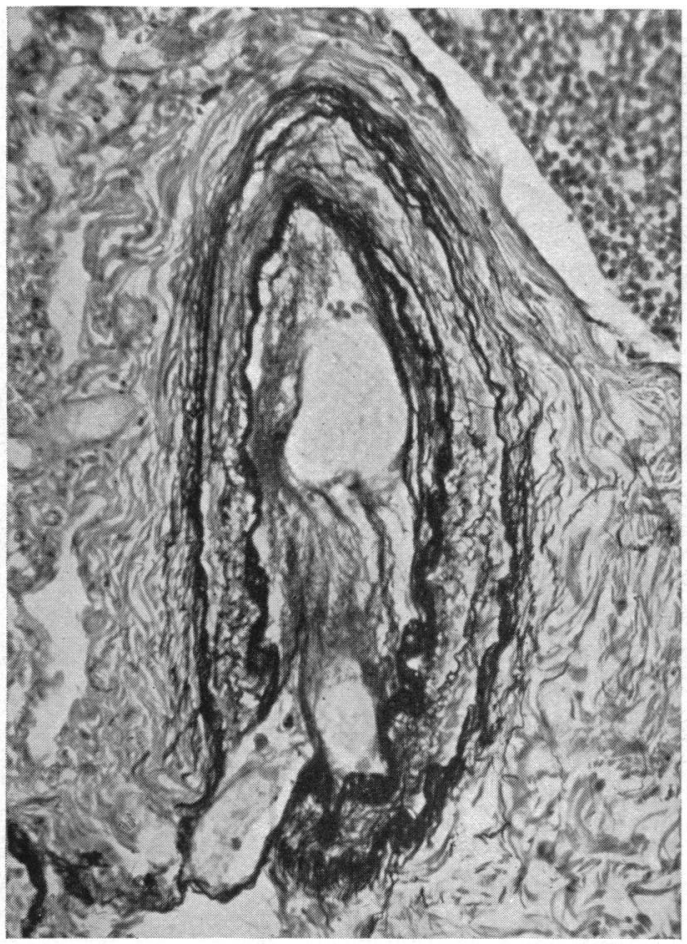

Fig. 7.-Transverse section of the muscular pulmonary artery. The elastic membranes are thick and there is elastic tissue in the media and adventitia. The lumen of the vessel has been obliterated by fibro-elastic tissue. Recanalization has occurred. A branch is emerging from the parent vessel (Stain, Verhoeff/Van Gieson, ×210).

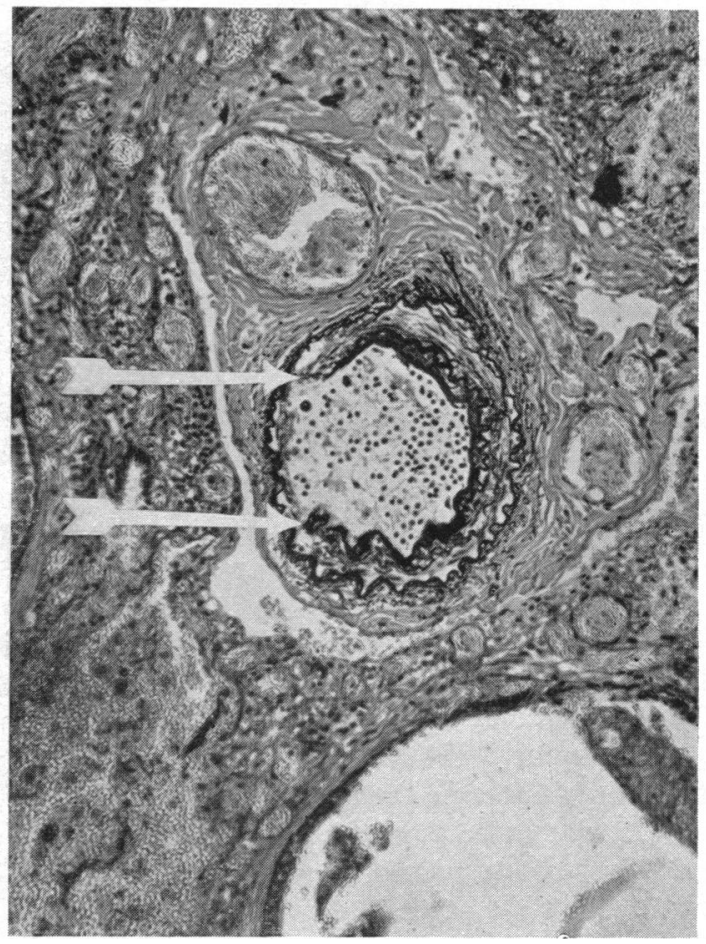

FIG. 8.-Transverse section of a muscular pulmonary artery. Aplasia of the media is seen between the points indicated by arrows. At these points the internal and external elastic laminæ fuse to form a single lamina seperating the adventitia and the proliferated fibrous tissue occluding the lumen of the vessel (Stain, Verhoeff/Van Gieson, x 122).

Fig. 9.-Transverse section of a muscular pulmonary artery. $A$ blood filled sac (B) is seen in communication with the artery (A). This sac proved on serial section to be a grossly dilated branch of the parent vessel. The external elastic lamina has ruptured opposite the emergence of the dilated brach (Stain, Verhoeff/Van Gieson, × 122).

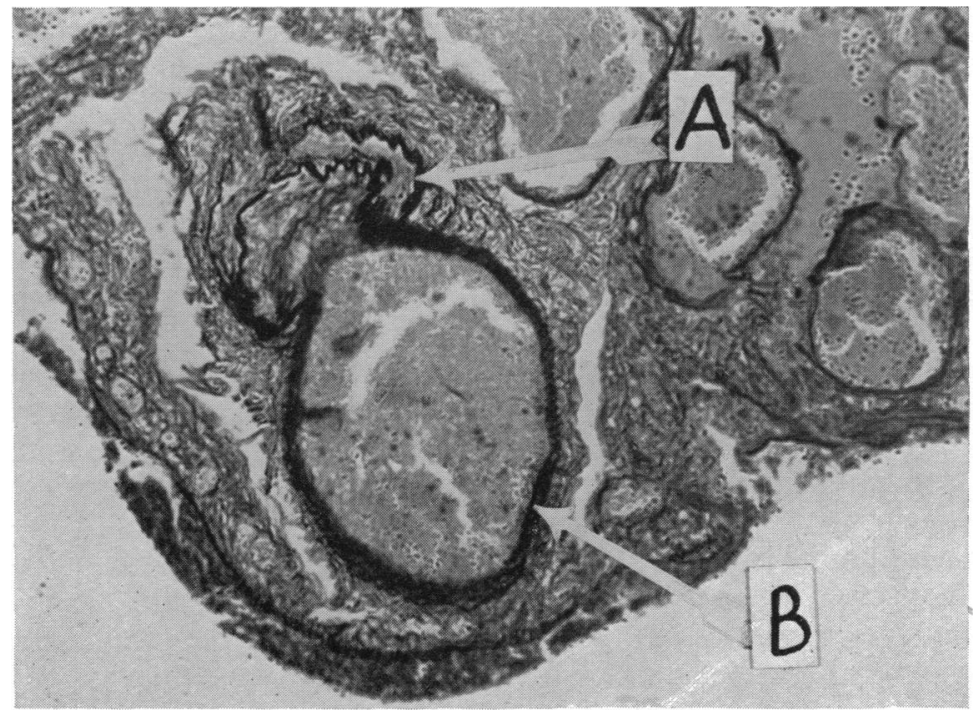


exertion, indicating that, as in some cases of defects of the membranous septum, a muscular defect of the interventricular septum may be complicated by pulmonary hypertension, right ventricular hypertrophy, and reversal of flow through the defect. Such complications were probably present in the case of Weiss (1927), where there was severe central cyanosis and in that of Konar and Sen Gupta (1954), where it was noted that the second pulmonary sound was loud and split and there was moderate cyanosis. Another patient with a muscular defect seen by one of us (J.W.B.) also had clinical signs of pulmonary hypertension. This boy had suffered from breathlessness on exertion and frequent chest infections, and died at the age of seven years from bronchopneumonia which was accompanied by central cyanosis but not congestive heart failure.

A harsh systolic murmur such as one heard in the present case has been present in all the reported cases (Weiss, 1927; Konar and Sen Gupta, 1954; Hemsath et al., 1936; Edwards et al., 1954; Kaplan and Robinson, 1954), and in the case of the boy mentioned above but there is no evidence that the maximum site of this murmur and its distribution allows it to be distinguished from the murmur of a septal defect in the membranous part of the inter-ventricular septum and the differentiation of these two conditions will probably only be made at necropsy.

Right ventricular hypertrophy appears to be a common feature of the anomaly. There was cardiographic evidence of right ventricular hypertrophy in the present case (Fig. 1) and also in the patients reported by Weiss (1927) and Konar and Sen Gupta (1954), which are the only previously reported patients where an account is given of the cardiographic findings. On radiological examination, there was right ventricular hypertrophy in the present patient and in that reported by Konar and Sen Gupta (1954). There was also cardiographic and radiological evidence of right ventricular hypertrophy in one patient previously seen by one of us.

Muscular defects may occur in the inter-ventricular septum in the region of the apex or midway between apex and membranous septum. In the case described by Konar and Sen Gupta (1954) the defect was in the apical region while in the case of Weiss (1927) it was midway between apex and mitral valve, and in the present patient it was in the lower third of the muscular septum. Brown and Gerlis (1954) have demonstrated two examples of ventricular septal defects that occurred in the central area of the muscular septum and were associated with dilatation of the main pulmonary artery and right ventricular hypertrophy, suggesting that pulmonary hypertension was present in life. Hemsath et al. (1936) reported the co-existence of muscular and membranous defects. Wimsatt and Lewis (1948) considered that defects of the ventricular septum are produced by aneurysmal dilatation of sinusoidal communications which occur in the septum developing between right and left ventricles as described in the pig embryo up to the 45-mm. stage by Bennett (1936). Examples of muscular defects in the ventricular septum have been described in animals. Olafson (1939) found in a calf an oblique defect similar to that described in a human being by Weiss (1927) and Wimsatt and Lewis (1948) described a large apical septal defect in a yak.

In addition to having a ventricular septal defect in an unusual site the present case is of interest for the histological appearances in the pulmonary arteries which have not previously been described in patients with muscular defects. Adventitial fibrosis, medial hypertrophy, and subintimal proliferation with eventual obliteration of the lumen by fibrous or fibro-elastic tissue showing recanalization occur in pulmonary arteries of patients with congenital heart disease complicated by severe pulmonary hypertension. Medial aplasia has been reported in the muscular pulmonary arteries in other forms of cardiac disease associated with pulmonary hypertension by Evans (1951) who believes that the combination of defective arterial wall and pulmonary hypertension lead to endarteritis fibrosa producing arterial obstruction and increasing the pulmonary hypertension. The unique feature in this case is the dilatation of the branches of the muscular pulmonary arteries occurring at the same site as medial aplasia. The recurrent hæmoptyses in the terminal phase of the patient's life were probably due to rupture of these vessels under the strain of pulmonary hypertension. Since hæmoptysis frequently occurs in patients with congenital heart disease complicated by severe pulmonary hypertension, the possibility that this is the result of rupture of dilated branches from pulmonary arteries should be borne in mind. 


\section{SUMMARY}

A case of a muscular defect in the ventricular septum is described. The patient presented in life the picture of cyanotic congenital heart disease with pulmonary hypertension and died following a severe hæmoptysis. In addition to the usual histological features associated with severe hypertension the pulmonary arteries showed the unique feature of aneurysmal dilated branches arising from the muscular arteries.

We wish to thank Mr. C. Lambourne for his invaluable help with the sections.

\section{REFERENCES}

Bennett, H. S. (1936). Amer. J. Anat., 60, 27.

Brenner, O. (1935) Arch. interm. Med., 56, 21.

Brown, J. W., and Gerlis, L. M. (1954). A Visual Atlas of Congenital Heart Disease (slides 19 and 20). Harvey and Blythe, London.
Heath, D., and Whitaker, W. (1955). Brit. Heart J., 17, 273.

Edwards, J. E., Dry, T. J., Parker, R.L., Burchell, H. B., Wood, E. H., and Bulbulian, A. H. (1954). Atlas of Congenital Anomalies of Heart and Great Vessels. Blackwell Scient. Publ., Oxford, p. 62.

Evans, W. (1951). Proc. Royal Soc. Med., 44, 600.

Hemsath, F. A., Greenberg, M., and Shain, J. H. (1936). Amer. J. Dis. Child., 51, 1356.

Kaplan, H. S., and Robinson, S. J. (1954). Congenital Heart Disease. McGraw-Hill Company, New York, p. 106. Konar, N. R., and Sen Gupta, A. N. (1954). Brit. Heart J., 16, 224.

Olafson, P. (1939). J. Tech. Meth. Bull. Int. Assoc. Med. Museums, 19, 129.

Selzer, A. (1954). J. Amer. med. Ass., 154, 129.

Weiss, E. (1927). Arch. intern. Med., 39, 705.

Whitaker, W., Heath. D., and Brown, J. W. (1955). Brit Heart J., 17, 121.

Wimsatt, W. A., and Lewis, F. T. (1948). Amer. J. Anat., 83, 67. 